Arch. Vet. Scienc. 3(1):115-118, 1998

Printed in Brazil

\title{
DESENVOLVIMENTO DE MÉTODOS FÍSICOS PARA O ESTUDO DO COMPORTAMENTO BIOQUÍMICO E FISIOLÓGICO DE ORGANISMOS ANTÁRTICOS. I. POLARÓGRAFO COM ELETRODO DE OXIGÊNIO.
}

\author{
PEDRO HELIO LUCCHIARI ${ }^{1}$; MARIA IVETTE CARBONI MALUCELLI ${ }^{2}$; \\ MAURÍCIO BACILA ${ }^{3}$; MATEUS SUGIZAKI ${ }^{4}$; METRY BACILA ${ }^{5}$
}

\author{
${ }^{1}$ Departamento de Medicina, Pontifícia Universidade Católica do Paraná - PUCPR, Curitiba-Pr. ${ }^{2}$ Instituto \\ Butantan, São Paulo-SP. ${ }^{3}$ Centro de Ciências Agrárias e Ambientais, Pontifícia Universidade Católica do Paraná \\ - PUC-PR, São José dos Pinhais, PR. ${ }^{4}$ Faculdade de Ciências, UNESP, Campus de Bauru-SP. ${ }^{5}$ Departamento de \\ Medicina, PUC-PR. Curitiba-Pr e Laboratório de Piscicultura, Curso de Pós-Graduação em Ciências \\ Veterinárias, Universidade Federal do Paraná.
}

\section{Introdução}

O oxigênio é um dos elementos químicos mais abundante na face da terra, ocupando cerca de $20 \%$ da atmosfera. Descoberto há cerca de 200 anos atrás, constitui a substância mágica que tem fascinado o homem por todos os tempos, sem a qual a vida na terra seria impossível. A importância do oxigênio para a vida despertou no homem o interesse em desenvolver métodos capazes de quantificá-lo. Historicamente, as primeiras medidas relacionadas à quantificação do oxigênio em tecidos e órgãos de animais procuraram determinar o seu consumo, por unidade de peso e tempo, em diferentes condições fisiológicas.

$\mathrm{O}$ estudo do comportamento bioquímico e fisiológico de organismos antárticos compõe aspectos muito significativos, por estar vinculado principalmente aos mecanismos biológicos de adaptação a temperaturas extremas. Nesse particular, os peixes antárticos, vivendo a temperaturas abaixo de $0^{\circ} \mathrm{C}$, fornecem material biológico de extremo interesse para estudos dessa natureza.

Com base nessas considerações, propôs-se a criação de metodologia própria para o estudo de diferentes aspectos do comportamento biológico desses animais. Nesse particular, foram projetados e desenvolvidos métodos especiais destinados, principalmente, ao estudo dos processos respiratórios, bem como para analisar os mecanismos oxidativos da respiração em mitocôndria isolada de órgãos e tecidos desses animais.

O trabalho de VOSS et al. (1963), em que descrevem um novo modelo de eletrodo de oxigênio, destinado ao estudo da respiração celular e mitocondrial, foi a referência básica para o início dos nossos trabalhos.

\section{Materiais e Métodos}

Buscando reproduzir a metodologia descrita por VOSS et al. (1963), projetamos um sistema com

Correspondência para: Prof. Pedro Helio Lucchiari, Departamento de Medicina, Centro de ciências Biológicas da Saúde, Pontifícia Universidade Católica do Paraná - PUC-PR. algumas modificações fundamentais, descritas por LUCCHIARI (1978), LUCCHIARI e HOSHINO (1980), MALUCELLI et al. (1995a e 1985b) e SUGIZAKI et al. (1997), onde a câmara de reação foi construída em acrílico, com tampa removível e parafusada ao corpo da câmara (Fig. 1).

O eletrodo polarográfico, construído segundo MICKEL et al. (1983), é introduzido na câmara através de um orifício na parte central da tampa, e foi montado numa única peça, incluindo no seu interior um sensor de temperatura (Fig. 2).

O circuito eletrônico (Fig. 3) para a medida da corrente polarográfica foi o mesmo utilizado por LUCCHIARI et al. (1984). O ganho do amplificador foi ajustado para $10 \mathrm{em} \mathrm{P3}$ e o zero em P4 com a entrada do amplificador em aberto. A saída do $\mu \mathrm{A} 723$ fornece uma tensão estabilizada de $2 \mathrm{~V}$ e o potenciômetro P1 permite o ajuste da tensão de polarização ao valor desejado.

O circuito eletrônico (Fig.4) do termômetro digital foi o mesmo usado por MALUCELLI et al. (1995a), MALUCELLI et al. (1995b) e SUGIZAKI et al. (1997). O circuito integrado LM334 fornece uma corrente constante que passa pelo diodo 1N914, escolhido como sensor de temperatura pela sua resposta linear da diferença de potencial em função da temperatura, na faixa de 0 a $40^{\circ} \mathrm{C}$.

$\mathrm{O}$ consumo de oxigênio e a temperatura no interior da câmara de reação são registrados num registrador potenciométrico de dois canais e o cálculo da velocidade de consumo de oxigênio e do coeficiente do controle respiratório foram descritos por VILLELA et al. (1973), MALUCELLI et al. (1995a) e SUGIZAKI et al. (1997). Considerou-se, na região linear da curva, arbitrariamente, um segmento de reta correspondente a uma queda na concentração do oxigênio e o respectivo tempo gasto (Fig. 5). A velocidade de consumo de oxigênio foi calculada pelo quociente da quantidade de oxigênio consumida pelo tempo gasto, usando a seguinte equação:

$$
\mathrm{VO}_{2}=\mathrm{SO}_{2} \mathrm{XVf} \mathrm{Xq} / \mathrm{Vp} \mathrm{XAX \textrm {t }}
$$

Onde : 
$\mathrm{VO}_{2}=$ Velocidade de consumo de oxigênio.

$\mathrm{SO}_{2}=$ Solubilidade do oxigênio na temperatura do experimento, expresso em $\mu \mathrm{MO} 2 / \mathrm{L}$.

$\mathrm{Vf}=$ Volume da solução tampão no interior da câmara de reação.

$\mathrm{Vp}=$ Velocidade do papel de registro. $\mathrm{t}=$ Distância no eixo das abcissas, correspondente ao tempo necessário para a quantidade q de oxigênio ser consumida.

$\mathrm{A}=$ Quantidade total de oxigênio no sistema.

Os parâmetros $\mathrm{A}$, t, e q são medidos em centímetros no papel de registro.

Fig. 1. Representação esquemática da câmara de reação utilizada no estudo da respiração em mitocôndria isolada de órgãos e tecidos animais. (A, B) Entrada e saída de água de um banho com circulação; (C ) Barra magnética; (D) Saída de lavagem da câmara de reação por meio de bomba de vácuo; (E) Orifício para introdução do eletrodo palarográfico; (F) Orifício para introdução dos componentes da reação; (G) Corpo da câmara; (H) Tampa; (I) Anéis de borracha para vedação; (J) Câmara de reação de $1,5 \mathrm{~cm}$ de diâmetro por $2,0 \mathrm{~cm}$ de altura, construída em acrílico e fixada no interior do corpo principal (MALUCELLI et al. Vaccine 13(3):268-272, 1995).

Fig. 2. Representação esquemática do eletrodo de oxigênio com o sensor de temperatura. (A) Acrílico; (B) Diodo; (C ) Anel de prata; (D) Platina; (E) Vidro (MALUCELLI et al. Vaccine 13(3):268-272, 1995). 
Polarógrafo com Eletrodo de Oxigênio

Figura 3. Circuito usado para medida da corrente polarográfica. $\mathrm{R} 1=5 \mathrm{KW} ; \mathrm{R} 2=2 \mathrm{KW}$; $\mathrm{R} 3=1,5 \mathrm{KW}$; 4 4 $=30 \mathrm{~W}$; $\mathrm{R} 5=$ $8,5 \mathrm{KW}$; R6 e R7 = 1KW; R8 = 10KW; P1 e P3 = 1KW e P2 = 10KW; C1 = 0,1F e C2 = 100 pF.

Fig. 4. Circuito eletrônico do termômetro digital. A calibração da escala de temperatura foi feita através dos potenciômetros P1 e P2.

Fig. 5. Modelo gráfico para o cálculo da velocidade de consumo de oxigênio. 


\section{Discussão}

O desenvolvimento de um método específico para o estudo dos processos respiratórios e dos mecanismos de respiração e de fosforilação oxidativa em mitocôndria de órgãos e tecidos animais, ensejou para a sua utilização imediata na avaliação da viabilidade da vacina BCG liofilizada. MALUCELLI et al. (1995a e 1955b) desenvolveram um longo trabalho experimental comparando os resultados obtidos com o método polarográfico com outros métodos na avaliação da viabilidade da vacina BCG liofilizada. Estes estudos demonstraram que o método polarográfico é mais eficiente quando comparado com outros métodos pelas seguintes razões: maior sensibilidade; execução mais simples; exige quantidades bem menores de material a ser analisado, maior rapidez na obtenção de resultados; baixo custo do equipamento.

NIERO e MALUCELLI (1995) evidenciaram a possibilidade do uso do método polarográfico na avaliação do crescimento da Mycobacterium fortuitum em diferentes meios de cultura.

BACILA et al. (1989) estudaram as propriedades fosforilantes de mitocôndria isolada de músculo estriado de "ice-fish" Chaenocephalus aceratus e SUGIZAKI et al. (1997) verificaram a influência da temperatura na fosforilação oxidativa e no controle respiratório de mitocôndria isolada de fígado, músculo cardíaco e encéfalo do peixes antártico Notothenia neglecta, utilizando o mesmo instrumento no estudo.

Por outro lado, um importante avanço no método reside no fato de que o eletrodo de platina e o de referência $(\mathrm{Ag}-\mathrm{AgCl})$ foram montados numa única peça, englobando um sensor de temperatura que permite controlá-la mesmo durante o processo respiratório.

A análise dos resultados obtidos com o uso do método descrito na avaliação dos mecanismos de respiração de células isoladas e de mitocôndria de orgãos e tecidos animais, quando comparados com os de outros métodos, permite que se acrescentem as seguintes vantagens ao método polarográfico: menor tempo gasto em cada determinação, cerca de 15 minutos; menor quantidade de material biológico necessário para os testes; sensor que permite leitura direta da temperatura durante a respiração; facilidade de construção e de manejo; mais baixo custo; maior sensibilidade.

\section{REFERÊNCIAS}

BACILA, M.; ROSA, R.; RODRIGUES, E.; LUCCHIARI, P.H.; ROSA, C.D. Tissue metabolism of the ice-fish (Chaenocephalus aceratus) Loemberg. Comp. Biochem. Physiol. 92B(2):313-318, 1989.

LUCCHIARI, P.H.; HOSHINO, K. Inovação de circuito polarográfico para a determinação de variações dos níveis de oxigênio em meios biológicos. Rev. Ciênc. Bioemd. 1:51-62, 1980.

MALUCELLI, M.I.C.; NIERO, R.; LUCCHIARI, P.H.; BACILA, M. Evaluation of the polarographic technique for assay of the viability of freeze-dried BCG vaccine: I. The polarographic technique.Vaccine. 13(3):268-272, 1995a.

MALUCELLI, M.I.C.; NIERO, R.; LUCCHIARI, P.H.; SOUZA, M.D.C.; BRUZZO, C.; ALVES, R.C.B.; MIGUEL, O; BACILA, M. Evaluation of the polarographic technique for assay of the viability of freeze-dried BCG vaccine: II. Viability of the vaccine assessed by polarography, Warburg respirometry and colony counting. Vaccine. 13(3):268-272, 1995b.

MICKEL, T.J.; QUETIN,L.B.; CHILDRESS， J.J. Construction of a polarographic oxygen sensor in the Laboratory. In: Polarographic Oxygen Sensors. Aquatic and Physiological Application. Ed. E. Gnaiger and H. Foster, New York, Spinger-Verlag, Pg 81, 1983.

NIERO, R.; MALUCELLI, M.I.C. Feasibility of the polarographic method for the evaluation of the Mycobacterium fortuitum growth in different culture media. Rev. Ciênc. Farm. São Paulo, 16:147-154, 1995.

SUGIZAKI, M.; LUCCHIARI, P.H.; MALUCELLI, M.I.C.; BACILA, M. Respiration and oxidative phosphorylation of mitochondria from tissues and organs of Antarctic fish. Proc. NIPR. Symp. Polar Biol. 10:145-152, 1997.

VILLELA, G.G.; BACILA, M.; TASTALDI, H. Técnicas manométricas. In: Técnicas e Experimentos de Bioquímica. Rio de Janeiro, Editora GuanabaraKoogan, p. 367, 1973.

VOSS, D.O.; COWLES, J.C.; BACILA, M. A new oxygen electrode model for the polarographic assay of cellular and mitochondrial respiration. Anal. Biochem. 6:211-222, 1963. 